\title{
Standard Cubic Foot
}

National Cancer Institute

\section{Source}

National Cancer Institute. Standard Cubic Foot. NCI Thesaurus. Code C68859.

A unit used in physical chemistry to express the amount of substance of an ideal gas in one cubic foot at 60 degrees Fahrenheit and pressure of one atmosphere. 